\title{
Digital Marketing Culture: An Exploration of Food Truck Business f rom Online Social Capital Perspective
}

\author{
A D Faozi ${ }^{1}$, A Yani ${ }^{2}$ \\ 1,2 Universitas Indonesia, Depok \\ 1achmad.dedi81@ui.ac.id, ㄹahmad.yani81@ui.ac.id
}

\begin{abstract}
Progress in the world of the food truck business today has given more attention to managing social media sites as an online marketing strategy. Some previous research also shows that the role of social media sites can be seen as a medium, a means and an online facilitator which directly causes significant changes in the composition of offline social capital. The dynamics of reciprocal relationships at every level of marketing online or offline tend to lead to social participation among food truck sellers and civil servant consumers. This study attempts to analyze how new forms of social capital and their links with the practice of the food truck business in Jakarta. A qualitative approach with a digital ethnographic method is used for data collection procedures in the field. The results of interviews conducted online and offline were analyzed using the Taxonomy Analysis method. The digital marketing process allows for feelings of sympathy in the form of admiration, attention, care, empathy, appreciation, responsibility and trust towards food truck sellers. The workings of online social capital in the realm of digital marketing can be seen through various existing sociocultural dimensions. These dimensions allow flexibility for the food truck business world to collaborate with other groups, participate digitally in distributing information on food products, online to co-operate and stimulate online networks or new outreach agencies.
\end{abstract}

Keywords: Online Social Capital, Food Truck Business, Digital Marketing

\section{INTRODUCTION}

Online marketing is part of digital marketing which means online marketing is under the 'umbrella' of Digital Marketing. The biggest difference is the online marketing technique that requires users to use the internet to carry out their marketing tasks. As technology develops, online marketing techniques also develop rapidly. So food truck sellers must be truly 'literate' and keep up with the latest technological developments. Examples of online marketing techniques are social media marketing (Facebook, Instagram etc.).

The dynamics of online marketing bring wider opportunities for the food truck business. Without publication through social media, it is certainly difficult for business people to be able to compete and attract many buyers from the Civil Servants community. Based on data from the Indonesian Food Truck Association reported that there are at least 70 food truck businesses that are already operating in the city of Jakarta [1]. The number of food truck sellers who went out of business in the beginning of operations has been relatively down and increased by 100 percent from the number of 30 entrepreneurs who have been recorded in 2017 [2]. Until 
now, the power of social capital that operates in the realm of social media marketing makes social marketing work more effectively. In addition to word-of-mouth or offline marketing, online marketing is an additional medium to "streamline" economic action by the Jakarta Food Truck Community.

One of the evidence supporting this argument is that there are still many members of the food truck seller who pay special attention to managing social media as a medium for forming social ties. The mechanism of social media marketing can be affiliated with feelings of sympathy in the form of admiration, attention, caring attitude, empathy, appreciation, sense of responsibility, or trust towards mobile food sellers [3]. Some research results also conclude that on the user side, online social capital is a product of online exchange that in many cases can be stated as a market commodity. Online social capital becomes a kind of offering to the social market when users try to utilize networks of friends, followers, views, and likes for a number of specific purposes [4]. The number of articles on how to improve online branding strategies, increased use of clicks, and online culinary campaigns arranged to develop business opportunities artificially which is evidence of the increasingly perceived importance of obtaining symbols or "likes" and followers on social media. This phenomenon shows the positive assessment of online consumers in practicing the values of reciprocal relationships in food buying activities.

In addition, the variety of fast food menus offered by the Jakarta Food Truck Community is widely marketed through social media or offline. Mobile food sellers make use of existing online social media to explore information resources as their resources for developing business. Every individual who wants to enter the social media space must include their personal information data to have an account and access. Information characteristics of social consumers, such as eating habits, eating patterns, where to eat, to favorite foods that are often consumed. This source of information is converted into a commodity which in terms of the food truck business can be used as an opportunity for business interests.

As a result, there are questions about how online social capital is positioned as a deliberate economic strategy by mobile food sellers, especially to encourage digital participation for the benefit of a business. The density of information available on the social media sites Instagram and Facebook is usually used by the Civil Servants Community to remain active in socializing, gathering with family and coworkers while eating or just eating snacks while exchanging stories and experiences on weekends (holidays). This is in line with social media marketing as the main accessibility for the mobile food vendors to do food product marketing online [4]. The movement to use social media as a means of additional social marketing media has been demonstrated by the increasing number of Civil Servants Communities participating in the food truck business process in the city of Jakarta.

In both examples, online social capital tends to involve the dimensions of individual social capital and collective social capital as sources within the structural ecosystem of digital networks. From the dimension of online social capital, the authors are interested in the process of distributing profits from the food truck business and how they do it. Therefore, this study was conducted to explore new forms of social capital in the realm of the practice of food trucks mediated by social media Instagram and Facebook that have been used by the Food Truck Community. This study aims to explain the process of forming the dimensions of online social capital as well as its relation to the food truck business activities. This research is important because there is no study of online social capital in the practice of the food truck business. Relevant studies only relate to the relationship between online social capital and conventional business activities. In addition, research conducted by Chieh-Peng revealed that the relationship of social capital by revealing the relationship of social capital with the use of instant messaging 
(IM) is a test model of data obtained from business organizations in Taiwan, and the results show that the indirect effect of social support on the use of IM through shared codes and languages is significant through business centrality. Online social capital operates in dimensions of social capital that includes a number of aspects, namely: commitment, reciprocity, shared codes and language, shared narratives, centrality, and network ties [5]. This also supports the researcher's argument that using online social media will not hamper the development of social capital and will not make the food truck business deserted buyers.

FIGURE 1. Schema of How to Work Social Capital in the Social Media Domain

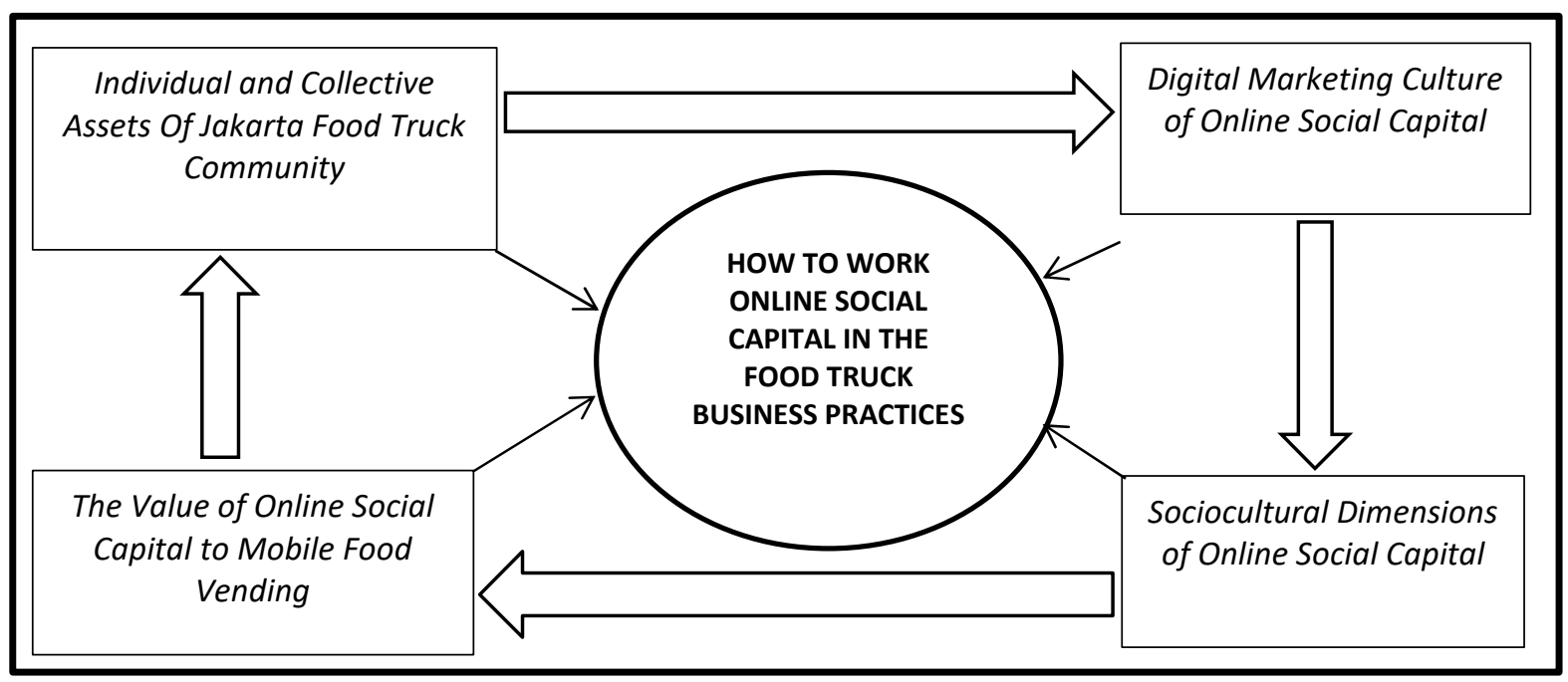

Source: Processed from Various Social Capital Reference Sources.

The performance of the Jakarta food truck community is always seen based on cultural capital and physical capital, such as money or assets. According to Adnan that: "This is of course inadequate because it ignores other aspects, such as intelligence, cooperation, trust, etc., and the concept of POPIS (physical capital, organizational capital, political capital, intellectual capital, social cultural capital) offers a perspective more comprehensive information about various capital influences the performance of the Jakarta food truck community "[6]. However, in reality among various food truck groups in Jakarta, there are some capital that is more dominant than the performance of another community that clearly shows the dominant role of offline sociocultural capital in influencing the economic success of the Jakarta food truck community.

A study of online social capital on a social media medium was conducted by ShwuMin, et al in 2016 which showed that: "which were based on 970 effective samples of Facebook users, supported several findings. Both SNS behavior and social capital affect SCI, while the relationship between SNS behavior and SCI is partially mediated by the bonding and bridging social capital. The results also show that browsing of SNS behavior has a stronger impact than participating of SNS behavior on either bonding or bridging social capital. In addition, bridging social capital has a stronger influence than social capital bonding on the giving intention of social commerce "[7]. In another study conducted by Boase and Wellman in 2006 relatively showed that internet users or online social media, usually have a wider level of social networking than those who do not use the internet as a communication media tie [8]. In addition, research from Ellison et al. Stated that social capital conducted online is the result of 
relationships that are formed offline; where bridging social capital is made possible through the "maintenance" of social relations. Among the respondents of this study, social capital that was built online exclusively created a weaker bond [9]. Differences in social ties are offered by Ellison et al who demonstrate the strong social ties that are made possible through social media [10]. Online social capital provides easy individual access to information which results in benefits such as creating connections in work connections. In addition, social capital researchers from Bargh and McKenna have found various forms of social capital, including in terms of social ties with friends and neighbors [11]. These studies show that the socio-cultural phenomenon of using online social media as a tool to create new forms of social capital is not nonsense. This online social capital has become a relatively new discovery as an alternative in an effort to bridge the perspective of the difference between offline social capital and online social capital that yields better results for the latest development of social capital theory in the science of Sociology itself.

\section{RESEARCH METHOD}

This research uses a qualitative approach. Qualitative research is a research approach that focuses on in-depth tracking of selected viewpoints of informants from civil servant consumers and the Jakarta Food Truck Community. Mobile food sellers as the main subject in the meaning process behind the use of social media marketing. This study is related to how subjects think, live, and behave in the context of food truck business practices. The key informant retrieval technique was obtained by selecting initial information through the help of several gatekeepers. This is done to focus on using the capital of people who have been known before. Researchers try to contact key informants (food truck vendors) through the closest person. This method is seen as more effective, because researchers can express their intentions more freely. Of course the socio-cultural dimension of digital marketing becomes a unique event that is rarely observed by most people. The object of this research study is online social capital, especially in the realm of food truck practice. Data obtained from the field (fieldwork) are then analyzed using the Taxonomy Analysis framework. The digital ethnographic method is used as a strategy of data collection procedures in the field [12]. The results of interviews conducted online and offline are interpreted by researchers in a tick description. The stages in this model consist of four stages, namely data collection, data reduction, data presentation and drawing conclusions [13]. The stages are of course preceded by a variety of pre-research, including: need careful preparation and be able to establish good cooperation with food truck consumers and members of the Jakarta Food Truck Community. By jumping directly to the location of selling and researchers take original data and not only secondary data.

\section{RESULTS AND DISCUSSION}

This section explains the results of the analysis of offline and online interviews obtained from key informants and additional informants, namely the Jakarta Food Truck Community and also some civil servant consumers who have been actively involved in the food truck business. According to Hardjosoekarto who said that the dimensions of social structure, culture, and social processes can be identified in the field of online marketing promoted by the Jakarta food truck community. This community believes that the same aspects of digital economic development can be explored in many other food business sectors [14]. Information obtained from the field in four sociocultural dimensions of online social capital in the Jakarta Food Truck Community by using digital marketing symbols as part of the food truck business process in Jakarta. The 
dimensions of social capital according to Bain and Hicks as well as Nahapiet and Goshal consist of three dimensions of social capital, namely the cognitive, relational and structural dimensions [15]. These three dimensions are a form of conceptual framework to measure the existence of offline social capital at the community level. Besides these dimensions, in this study it turns out that other socio-cultural dimensions were found. The dimension in question is a digital participational dimension. Cognitive, relational and structural dimensions as dimensions intersecting with the dimensions of digital participation. All dimensions were found to work in the dynamics of the emergence of online social capital in the realm of food truck business or practice. This is in line with an offline interview conducted with Ridho (Owner of Dimsumsoe Food Truck) saying that:

which occurs in the field because our food products are few and the lack of focus on products and the lack of products is what makes the lack of marketing directly because it may be seen by people or consumers differently from the way that occurs in the field and we see an opportunity for now, to take advantage marketing in terms of social media sites and we do sales on trial with only relatives or closest relatives first

The researcher found the three dimensions of the sociocultural as a framework for understanding deeply the level of online social capital. The first dimension is called the cognitive dimension. This dimension is very closely related to values, attitudes and beliefs that affect trust, solidarity and reciprocity relationships. Interview with Wanti (Cireng Sinden Owner), revealed the following sentence:

in terms of product sales, digital marketing may be carried out in social media but it has not been effective because there is no direct support application for the sale of food truck products, secondly, it is rather difficult creativity in terms of creating ideas about slabs because in Jakarta here, cireng traders a lot, maybe more than my own foodtruck concept to make it more interesting

Sociocultural aspects drive towards the creation of online collaboration into the food truck business practice system in order to achieve common goals. Each food truck group actually has a cognitive dimension or can also be referred to as this cultural dimension, even in different levels of online social capital. Food truck sellers have digital cultural values as online social capital that enables harmonious social relationships to be maintained, both fellow food truck members internally and with different communities. Meanwhile, certain food truck businesses emphasize the aspects of solidarity and cooperation within their own groups and traditionally do not have guidelines for interacting well with other groups online. This result is supported by an offline interview with Arman and Wistan (Owner of Es Goyobod Foodtruck) saying that:

the most important thing is about products that are sold alone constrained from social media as a direct marketing media, secondly because I have always sold vehicles that I did not do upgrades or special designs because of my focus on the product

the first is the absence of applications that can specifically support the marketing of foodtruck itself, and the second puts forward the concept of the meaning or meaning of racing itself so that consumers are interested, and the third when 
talking about competitiveness with the same product I return to consumers, consumers may know more about the taste or the quality itself

In the digital cultural values of the Jakarta Food Truck Community there is basically a balance between online social capital that regulates harmony and social solidarity at the level of internal relations. The social relations that exist among fellow group members are referred to as social capital bonding which can enable the creation of online collaboration. Whereas the mutually beneficial relationship between food truck sellers and civil servant consumers is known as bridging social capital. It can be said as bridging social capital because it is able to bridge the differences that exist between food truck groups that have different cultural values and prioritize the similarities found on both sides. The food truck community in the city of Jakarta has cultural values which are a type of bridging social capital. This typology of social capital tends not to concern the group itself, is inclusive and is easily involved in the process of collaboration with other groups. Conflict in the realm of online social media marketing will be easier for both parties to not have the bridging social capital capacity.

The second dimension of online social capital is the structural dimension in the form of structure, the scope of the Jakarta Food Truck Community at the local level. This dimension tends to accommodate and encourage collective activities that benefit all community members. This structural dimension plays an important role because of the effort to develop a food truck business to increase the economic values of online social media marketing activities. This online marketing practice will be more successful if done through social institutions at the local level. Following are the results of conversations with one of the food business owners in Jakarta:

sales of products that are carried out are still only on social media, not with other online marketing media, secondly competitiveness maybe we still have difficulty in selling times, because every month we can move around too, especially when there is an event. However, in the end, we as food trucks in Jakarta feel helped by the licensing concessions from the DKI Jakarta Government in terms of facilitating the rules for selling in the field and we also have a food truck business community which also supports the food business that we are currently operating this. Both of these aspects, I think, really helped us in the field

The structural dimension of online social capital which is generally in the form of social networks in institutional relationships receives important attention in examining the importance of online social capital in food truck business activities. The structural dimension attaches attention to the characteristics of the social system and the relation network as a whole. This term describes the impersonal configuration of the relationship between food truck sellers and other social groups. The structural dimension of online social capital refers to the overall pattern of relationships between food truck actors and who is reached and how we reach those people. Important sociocultural aspects of the structural dimension are the presence or absence of network ties between food truck actors in a network configuration frame or network morphology that describes the pattern of relationships of structural dimensions as measured by connectivity or network links, hierarchies or relationship levels, and the compatibility of the food truck community with other social groups. Online connectivity run by food truck sellers through social media sites tends to increase the contact or communication that can be used to improve information, economic resources and employment [16]. This is consistent with the results of an interview with Dirga (Owner of Mac Duren), saying that this relationship runs: 
seen as it is today marketing in terms of internet media has not been overemphasized because sales are tried with only to relatives or closest relatives first

The third dimension of online social capital is the existence of a relational dimension. This dimension illustrates the type of personal relationship that food truck actors have developed with other business people through historical interactions. This concept focuses on the special relationships that food truck sellers have, such as respect and friendship relationships, which influence the behavior of their food truck business. The finding of this aspect is done through ongoing individual relationships and fulfills every motive of the food seller himself. Like sociability, approval and prestige. This relational dimension refers to the wealth that is created and is greatly influenced through online business friendship relationships and behavior that shows the obligations of food truck sellers and also the trust between them. This relational dimension component refers to trust and trustworthiness, norms and online sanctions, obligations and expectations as well as online identity and identification of business goals. This dimension also describes the level of trust from social interactions because the key aspect of this dimension is online trust and with trust from food truck consumers and from the online process of social media marketing in the food truck business and then getting relationship exchanges.

\section{CONCLUSIONS}

The sociocultural dimension of online social capital is intangible assets. This aspect was created by food truck sellers from online social relations which created the freedom for the food truck business world to collaborate with other groups, participate digitally in order to distribute information on food products, online to co-operate and stimulate online networks or new socialization agents. As a result, it is impossible that the food truck business world will go bankrupt when they are still exposing the symbol of digital marketing through certain social media platforms. This implies that food truck sellers who serve civil servant consumers as media get sympathy and social support as well as absolute economic benefits.

Some of the food truck sellers are actively involved in online social media marketing activities. Especially at this time, some digital marketing techniques lead to several components of online social capital. The three sociocultural dimensions found were the expansion of social capital theory, especially from the perspective of online social capital by taking the case of the food truck business in the city of Jakarta. This discovery was made by exploring new forms of online social capital and the fact that they were indeed found in the field.

\section{REFERENCES}

[1] R. Wattimena, "Food Truck, Kaki Lima yang Tertata," Tempo.co, Jakarta, Aug-2018.

[2] D. M. Galih Gumelar, "Food Truck, Bisnis Baru Berisiko Sekaligus Beromzet Tinggi," CNN Indonesia, Jakarta, Aug-2015.

[3] S. Thornsbury, "Agricultural Economics Report," Agric. Econ., no. 628, 2006.

[4] K. X. Faucher, Social Capital Online: Alienation and Accumulation. 2018.

[5] C. P. Lin, "Assessing the mediating role of online social capital between social support and instant messaging usage," Electron. Commer. Res. Appl., vol. 10, no. 1, pp. 105114, 2011.

[6] R. S. Adnan, "Kekuatan Kapital-Kapital Kelembagaan: Belajar dari Dua Koperasi Sukses," Masy. J. Sosiol., vol. 15, no. 1, 2010. 
[7] S. M. Horng, C. L. Wu, and T. P. Liang, "How behaviors on social network sites and online social capital influence social commerce: The case of Facebook," Pacific Asia Conf. Inf. Syst. PACIS 2016 - Proc., 2016.

[8] J. Boase, B. Wellman, A. L. Vangelisti, and D. Perlman, "Personal Relationships: On and Off the Internet Forthcoming in the Cambridge Handbook of Personal Relationships Edited by," Cambridge Handb. Pers. Relationships, pp. 1-20, 2004.

[9] N. B. Ellison, C. Steinfield, and C. Lampe, "The benefits of facebook 'friends:' Social capital and college students' use of online social network sites," J. Comput. Commun., vol. 12, no. 4, pp. 1143-1168, 2007.

[10] H. Jiang and J. Carroll, "Social capital, social network and identity bonds: a reconceptualization," CT 09 Proc. fourth Int. Conf. Communities Technol., pp. 51-60, 2009.

[11] J. A. Bargh and K. Y. A. McKenna, "The Internet and Social Life," Annu. Rev. Psychol., vol. 55, no. 1, pp. 573-590, 2004.

[12] S. K. \& I. W. Suyadnya, Metodologi Penelitian Kualitatif Berbagi Pengalaman dari Lapangan. Jakarta: Raja Grafindo Persada, 2018.

[13] M. A. Miles, "Miles and Huberman (1994)- Chapter 4.pdf," in Qualitative Data Analysis: An Expanded Sourcebook, 1994.

[14] S. Hardjosoekarto, "Construction of Social Development Index as a Theoretical Research Practice in Action Research by Using Soft Systems Methodology," Syst. Pract. Action Res., vol. 25, no. 6, pp. 493-509, 2012.

[15] H. Bapuji and M. Crossan, "Co-evolution of social capital and knowledge: An extension of the Nahapiet and Ghoshal (1998) framework," Acad. Manag. 2005 Annu. Meet. A New Vis. Manag. 21st Century, AOM 2005, no. 1998, 2005.

[16] A.Warokka, H. Sjahruddin, S. Sriyanto, E. Noerhartati, K. Saddhono. "Digital marketing support and business development using online marketing tools: An experimental analysis". International Journal of Psychosocial Rehabilitation. Vol. 24 no. 1 pp. 1181-1188. 2020 